\title{
Analysis of Mechanical and Thermal Stresses in a Pressure Casting Machine Plunger
}

\author{
Jacek Jankowski ${ }^{*}$, Dariusz Kołakowski ${ }^{2}$, Bogusław Piotr Pisarek ${ }^{2}$ \\ 1 Department of Strength of Materials, Lodz University of Technology, 1/15 Stefanowskiego str., 90-924 Łódź, \\ Poland \\ 2 Department of Materials Engineering and Production Systems, Lodz University of Technology, \\ 1/15 Stefanowskiego str., 90-924 Łódź, Poland \\ * Corresponding author's e-mail: jacek.jankowski@p.lodz.pl
}

\begin{abstract}
The study discusses the thermo-mechanical stress distribution in the plunger of a cold chamber casting machine with a horizontal casting chamber in the stationary aspect. The main stresses as well as the reduced stresses were determined for four different strength hypotheses, two of which took into account different acceptable maximal tensile and compressive stresses. For comparative purposes, the calculations were performed for three different construction materials used for cold chamber pressure machine plungers: grey pearlitic cast iron, high silicon bronze and beryllium bronze, as well as one more type of bronze, which has not been used for plungers so far, i.e. aluminium-iron-nickel bronze, constituting the initial alloy for the newly-developed complex bronzes with high wear resistance and elevated strength.
\end{abstract}

Keywords: plunger, cold chamber pressure machine, thermo-mechanical stresses, equivalent stresses, different tensile and compressive strength

\section{INTRODUCTION}

Pressure casting of aluminium, magnesium and copper alloys is the basic technology of producing household appliances, as well as motor industry and aircraft ware, etc. $[10,13]$. The technological process, during pressure forming, is a very complicated issue, due to the occurrence of such phenomena as thermo-mechanical fatigue, creeping, erosion, cavitation, mould and metal component dissolution, adhesion, etc. Figure 1 schematically presents the construction of the pouring system for a cold chamber pressure machine with a horizontal casting chamber [27] (a) and an exemplary drawing of a pressure cast with the pouring system elements [14] (b). The characteristic phenomena affecting the efficiency and durability of the pouring system of a cold chamber pressure machine with a horizontal chamber have been shown in Figure 2 [16]:

1. It can be inferred from the literature analysis that the main focus has been put on the phenomena occurring mostly in the casting chamber, in reference to:

- Thermal deformation (Fig. 3) [12] and thermal fatigue [23],

- Temperature distribution in the cold casting chamber of a cold chamber pressure machine [24], (Fig. 4) [26],

- Modelling of the heat flow in the casting chamber [30],

- Selection of the casting chamber material [5].

- In reference to the plungers used in a cold chamber pressure machine, the literature concentrates on:

- Plunger movement profile [9], 
a)

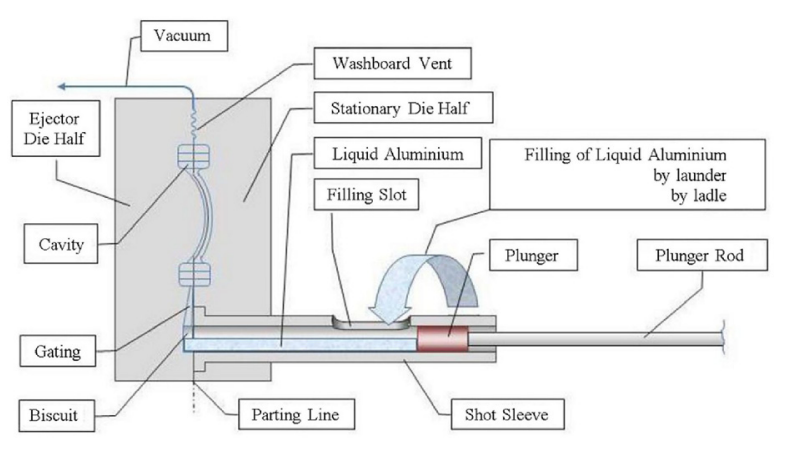

b)

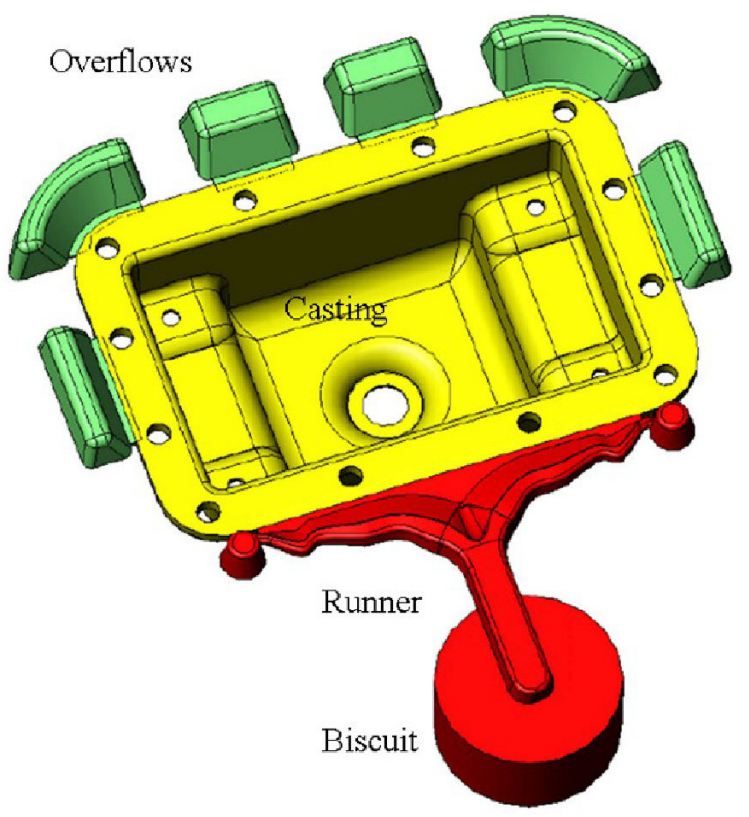

Fig.1. Schematics of a cold chamber pressure machine with a horizontal casting chamber [27]: (a) and a drawing of a pressure cast with the pouring system elements [14] (b)

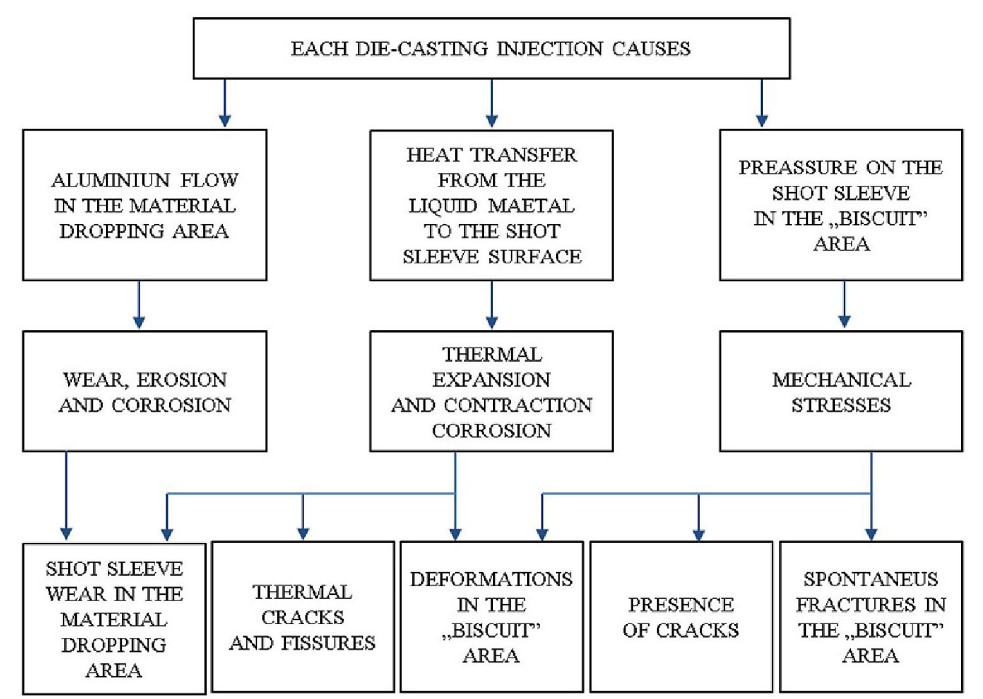

Fig. 2. Phenomena affecting the efficiency and durability of the pouring system of a cold chamber pressure machine with a horizontal casting chamber [16]

a)

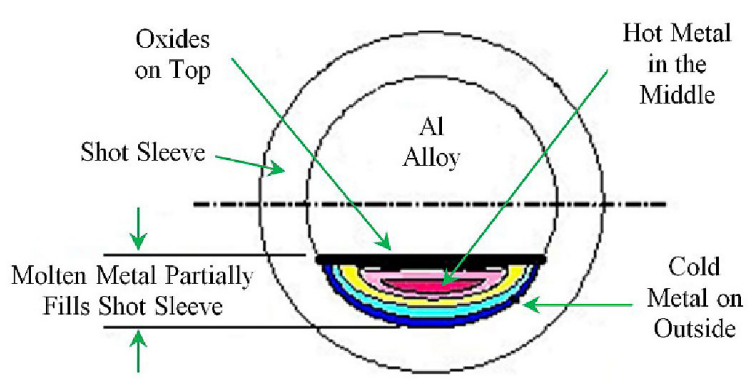

b)

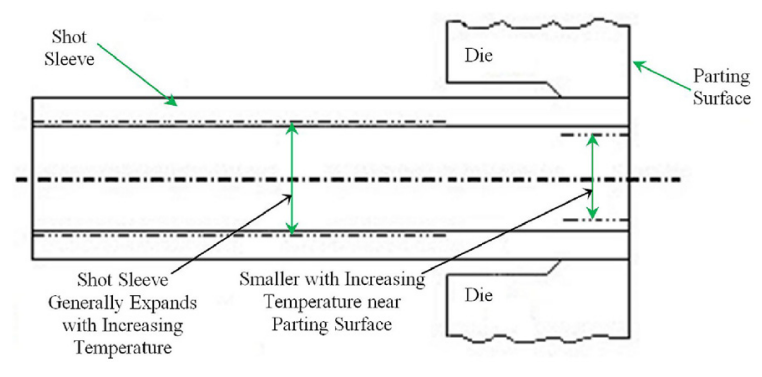

Fig. 3. Deformations of the chamber after liquid alloy casting [23]: a) laminar character of the alloy after chamber filling, b) changes in the chamber diameter with temperature increase, c) chamber deformations 


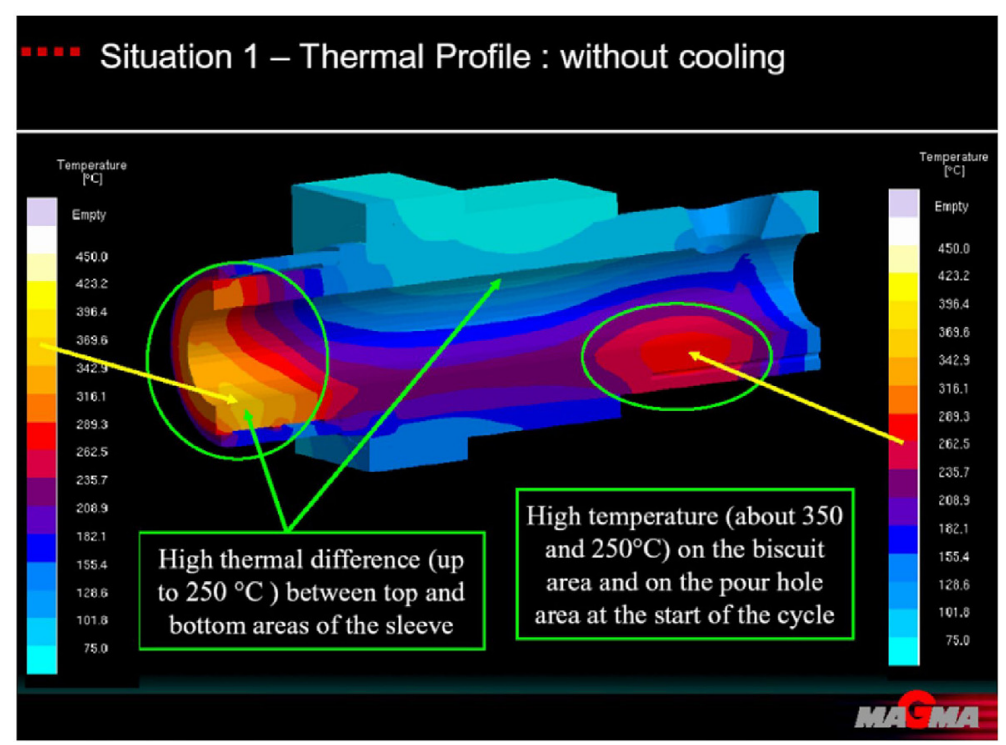

Fig. 4. Results of a temperature distribution simulation in a non-cooled casting chamber [26]

- Temperature distribution in the plunger depending on its material and wall thickness [5],

- Selection of the plunger material [5],

2. Simulation performed in the MAGMA5® program of the die casting of a thick-walled sleeve for cold chamber pressure machine plungers:

- Cold and hot cracking - a case study [21],

- Simulation of the stress in a die cast of a thick-walled sleeve during solidification and cooling [22],

- Optimization of the parameters for the die casting of a thick-walled sleeve [20],

- Plunger lubricants [8].

Based on the presented literature, it can be pointed out that no investigations of the stresses present in pressure machine plungers have been presented so far.

And so, the study concentrates on establishing the state of the thermo-mechanical stresses of the plunger of a cold chamber casting machine with a horizontal casting chamber. This is the first stage of investigations devoted to this issue. The article describes the stresses with the assumption of a uniform temperature field in the vicinity of the plunger. For comparative purposes, the calculations were performed for three different construction materials used for plungers of cold chamber pressure machines: grey pearlitic cast iron, high silicon bronze and beryllium bronze, as well as aluminium-iron-nickel bronze constituting the initial alloy for the newly-developed complex bronzes with high wear resistance and elevated strength $[18,19]$.
The following stages (planned articles) will include analyses of the stresses for a uniform temperature field, that is for conditions similar to the actual ones present during the operation of a plunger.

One of the causes of premature wear of the plungers is the interaction of the radial and circumferential thermal stresses with the external longitudinal stresses generated by the periodical input functions during the mould's operation.

In the established production cycle of pressure casting, after the start-up phase, it can be assumed that the radial and circumferential thermal stresses during one working cycle, due to a very high thermal capacity of the mould, are subjected to slight oscillations. Such a state is present after a few injections. The plunger is cooled for the whole working time through the forced circulation of the coolant.

In turn, the longitudinal mechanical stresses during the pressure casting work cycle change from zero through the injection pressure to the maximal compressive pressure. The whole cycle together with the time of the chamber's filling with the liquid metal lasts about 2-3 minutes, whereas the cycle of loading the plunger with pressure is below $60 \mathrm{~s}$.

In the case of the plunger of a cold chamber casting machine with a horizontal casting chamber, the compressive pressure is the minimal (compressing) longitudinal load equalling even up to $100 \mathrm{MPa}$, whereas the maximal load is zero during the chamber filling, i.e. it equals $0 \mathrm{MPa}$. 
The most important task is to determine the maximal thermo-mechanical stresses, including the reduced stresses. The materials used for plungers have different tensile and compressive strengths. The compressive strength $\mathrm{Rc}$ is much higher than the tensile strength $\mathrm{Rm}$. This means that the maximal acceptable compressive stresses $\mathrm{kc}$ are higher than tensile stresses $\mathrm{kr}$ (i.e. $\mathrm{kc}<\mathrm{kr}$ ). The study introduces the coefficient of compressive strength and tensile strength $\mathrm{z}=\mathrm{kc} / \mathrm{kr}>1$. Also, it takes into account the hypotheses referring to different maximal compressive and tensile stresses (the so-called Burzyński and Mohr hypothesis).

From the point of view of fatigue strength, the working cycle of the plunger in a casting machine is a negative pulsating cycle. The knowledge of the static maximal mechanical and thermal stresses is a necessary element which helps increase the durability of the plunger as well as its efficiency during the operation in the pressure machine. The study presents an analysis of four different plunger materials.

The study constitutes an introduction into analyses of the thermo-mechanical stresses present in the technological process. In order to facilitate the analysis, the study assumes an axisymmetric stress state with a three-directional stress state. In the lateral plane to the plunger axis, we observe radial and circumferential thermal stresses caused by the temperature difference between the outside and the inside of the plunger, whereas in the longitudinal direction, mechanical stresses occur. In the technological process, the thermal stresses change circumferentially from maximal in the lower part of the machine's casting chamber to minimal in the upper part of the chamber. For these reasons, the study also includes an analysis of the stresses additionally for two plunger temperatures. The analysis was performed for the maximal - in respect of the absolute value - static loads generating constant thermo-mechanical stresses, by means of analytic formulas used to determine them.

In the compression cycle of a casting machine, the plunger can impact on the pilot sleeve together with the die of the machine in which the sleeve is mounted. Then, a radial load additionally appears on the external surface of the sleeve. This has also been taken into account in the analysis of the plunger's operation.

The plunger analysis presented in the study is based on a representation of the actual pressure casting process performed on a Bühler machine at WIFAMA-PREXER, Łódź [25] (Fig. 5).

In the following studies, the authors are planning to consider the variability of the radial and circumferential thermal stresses as well as the variability of the longitudinal stresses.

\section{FORMULATION OF THE PROBLEM}

In order to conduct analysis, special program was made, that basic assumptions and formula were shown in figure 6. In help of the program, principal stresses are obtained for thermal and mechanical loads. For thick plunger cylindrical coordinates system was taken into consideration. Investigated issues of mechanical-thermal loads are linear, so that the principle of superposition can be used as principle that is broadly used in the mechanics of elasticity and strength of materials. a)

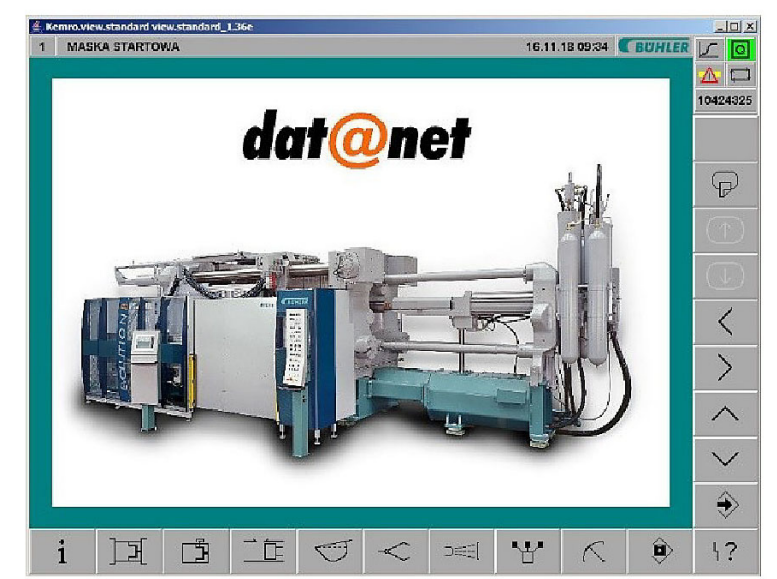

b)

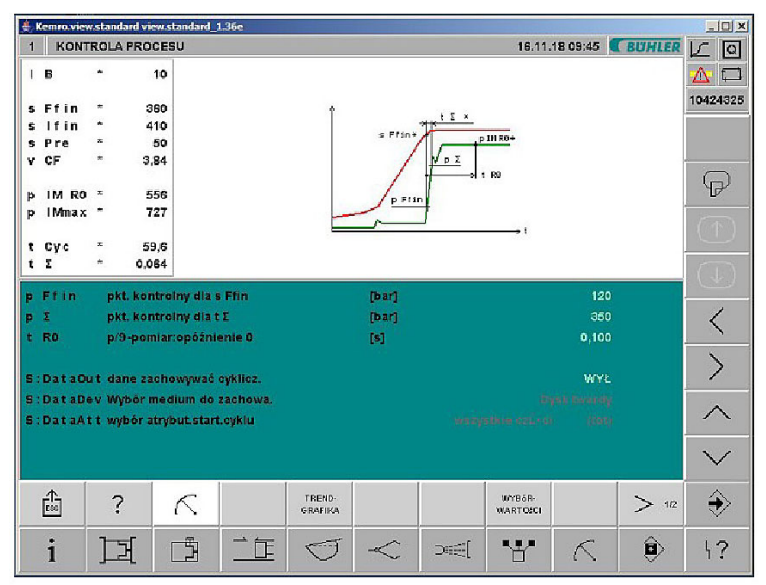

Fig. 5. A cold chamber pressure machine Bühler (WIFAMA-PREXER Łódź, Poland) [25] 


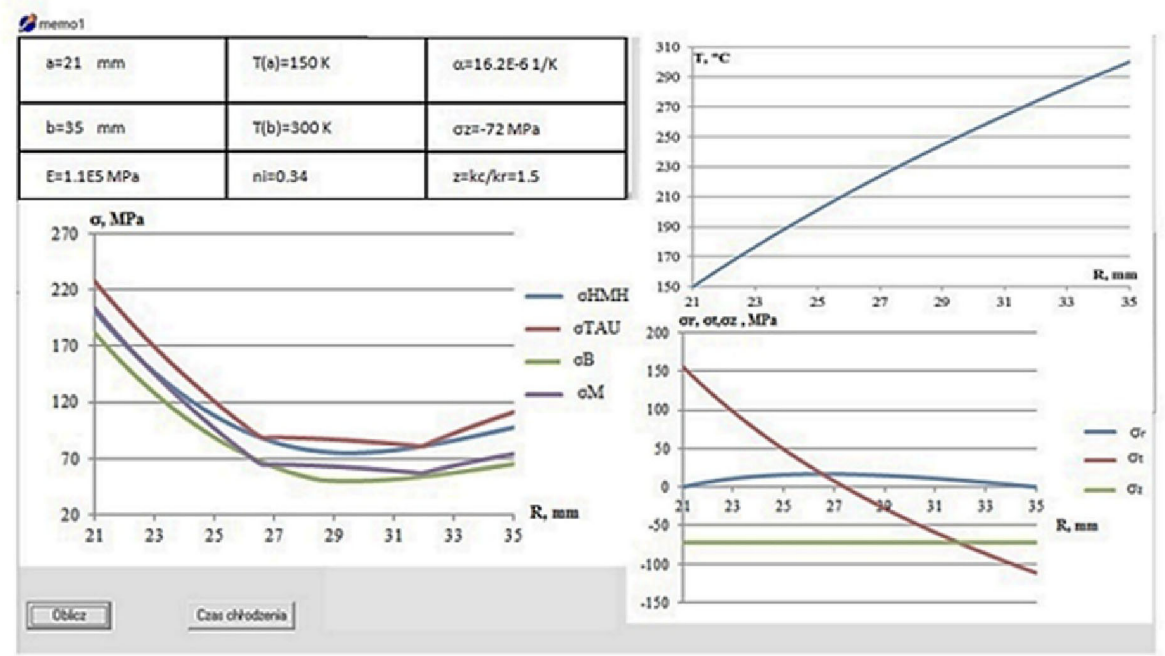

Fig. 6. Dialog window of the program

\section{Thermal stresses in thick-walled plunger for stationary problem}

Radial and angular stresses are principal thermal stresses for stationary problem.

In order to obtain basic equations for stationary problem, following assumptions were adopted $[6,15,28]$ :

- Kelvin phenomenon is neglected (deflection of the material causes growth of temperature),

- Lack of source of heat energy $(Q=0)$,

- Field of temperature is obtained independently on stresses and strains from classic equation of conductivity, for stationary problem,

- Temperature distribution is axi-symmetrical and does not depend on $\mathrm{z}$ coordinate in axial direction,

- Thermal stresses are caused by constant field of temperature (unchanged in time),

- Thermal and elastic properties material of tube are not dependent on temperature.

In analysed case, basic equation of the problem are taken into consideration $[6,28]$ :

- conductivity equation in stationary problem (1):

$$
\nabla^{2} T=\frac{1}{r} \frac{\partial}{\partial r}\left(r \frac{\partial T}{\partial r}\right)=0
$$

- equilibrium equation (2):

$$
\frac{d \bar{\sigma}_{r}}{d r}+\frac{\bar{\sigma}_{r}-\bar{\sigma}_{t}}{r}=0
$$

- geometric equations (3) i (4):

$$
\varepsilon_{r}=\frac{d u}{d r}
$$

$$
\varepsilon_{t}=\frac{u}{r}
$$

where: $u$-radial displacement,

$\varepsilon_{r}$ - radial strain,

$\varepsilon_{t}-$ angular strain,

$\bar{\sigma}_{r}$ - radial stress,

$\bar{\sigma}_{t}$ - angular stress,

$a$ - inner radius of tube,

$b$ - outer radius of tube (condition:

$a \leq r \leq b)$,

$T(r=a)=T_{a}-$ temperature on inner surface of tube,

$T(r=b)=T_{b}-$ temperature on outer surface of tube.

\section{Distribution of thermal stresses}

Radial and angular stresses are principal thermal stresses for stationary problem. IN figure 7 , geometry of plunger of cold chamber pressure machine.

Solution of equation (1) for plunger analysed can be written in form (5):

$$
T(r)=T_{a}+\left(T_{b}-T_{a}\right) \frac{\ln r / a}{\ln b / a}
$$

Relationships between stresses and strains for three-dimensional stress state are as follows (6):

$$
\begin{aligned}
& \varepsilon_{r}-\alpha \Delta T=\frac{1}{E}\left[\bar{\sigma}_{r}-v \vec{\sigma}_{t}-v \bar{\sigma}_{z}\right] \\
& \varepsilon_{t}-\alpha \Delta T=\frac{1}{E}\left[\bar{\sigma}_{t}-v \bar{\sigma}_{r}-v \bar{\sigma}_{z}\right] \\
& \varepsilon_{z}-\alpha \Delta T=\frac{1}{E}\left[\bar{\sigma}_{z}-v \bar{\sigma}_{r}-v \bar{\sigma}_{t}\right]
\end{aligned}
$$




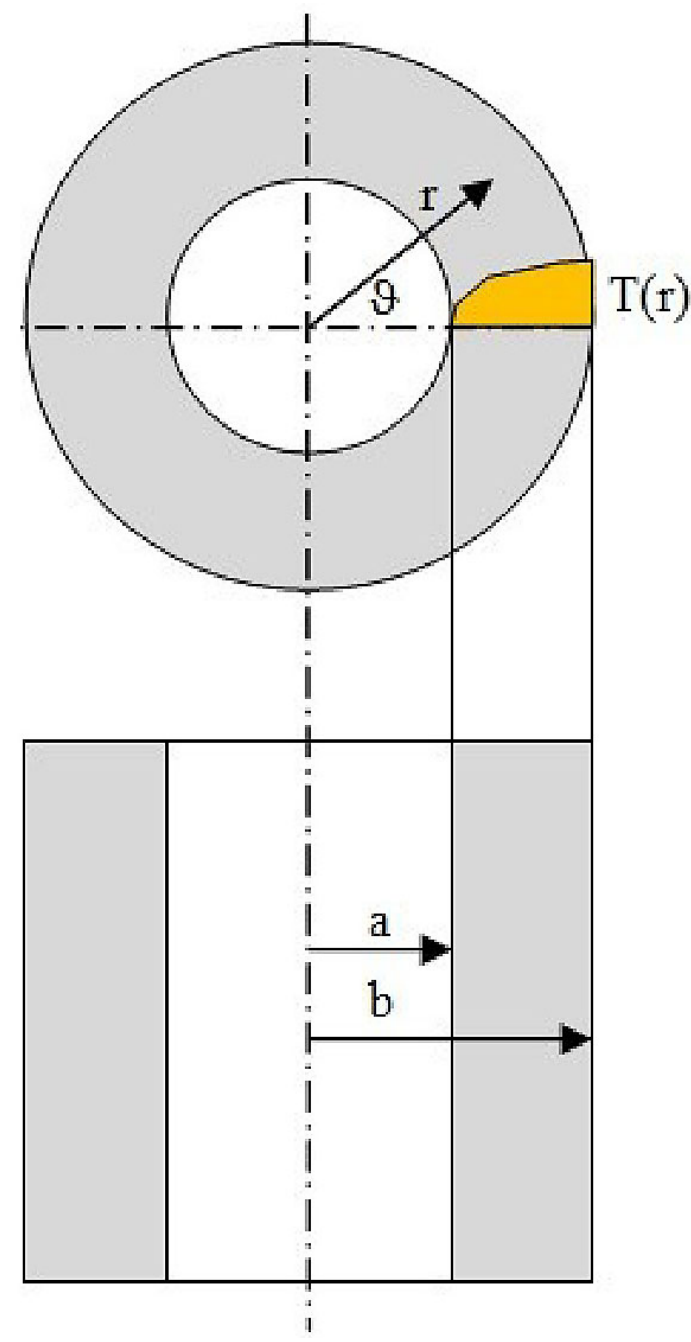

Fig. 7. Model of long thick-walled tube-plunger

where: E - Young modulus,

$v$ - Poisson's ratio,

$\alpha$ - coefficient of linear expansion,

moreover (7):

$$
\Delta T=T-T_{r e f}
$$

and (8)

$$
T_{r e f}=\min \left(T_{a}, T_{b}\right)
$$

The following inverse expressions come from (6) and can be written in the form (9):

$$
\begin{aligned}
& \bar{\sigma}_{r}=\frac{E}{\left(1-v^{2}\right)}\left[\varepsilon_{r}+v \varepsilon_{t}+v \varepsilon_{z}-(1+v) \alpha \Delta T\right] \\
& \bar{\sigma}_{t}=\frac{E}{\left(1-v^{2}\right)}\left[\varepsilon_{t}+v \varepsilon_{r}+v \varepsilon_{t}-(1+v) \alpha \Delta T\right] \\
& \bar{\sigma}_{z}=\frac{E}{\left(1-v^{2}\right)}\left[\varepsilon_{z}+v \varepsilon_{r}+v \varepsilon_{t}-(1+v) \alpha \Delta T\right] .
\end{aligned}
$$

For investigated problem, boundary conditions were accepted, assuming that radial stress is equal to 0 on inner and outer surface of tube (10):

$$
\bar{\sigma}_{r}(r=a)=\bar{\sigma}_{r}(r=b)=0
$$

Equilibrium equation in displacement after taking into account (2), (3), (5) i (9) has form (11):

$$
\frac{d}{d r}\left[\frac{1}{r} \frac{d(r u)}{d r}\right]=(1+v) \alpha \frac{d(\Delta T)}{d r}
$$

Components of stress state are found as solution of equation (10), taking into account dependences (3), (4), (5), (6), (9) and boundary conditions (11). Finally, components are obtained as follows (12):

$$
\begin{aligned}
& \bar{\sigma}_{t}=-\frac{E \alpha\left(T_{a}-T_{b}\right)}{2}\left[\frac{\ln (b / r)-1}{\ln (b / a)}+\frac{\left(b^{2} / r^{2}+1\right)}{\left(b^{2} / a^{2}-1\right)}\right] \\
& \bar{\sigma}_{r}=-\frac{E \alpha\left(T_{a}-T_{b}\right)}{2}\left[\frac{\ln (b / r)}{\ln (b / a)}-\frac{\left(b^{2} / r^{2}-1\right)}{\left(b^{2} / a^{2}-1\right)}\right]
\end{aligned}
$$

As it can see easily in (12), radial and angular stresses are dependent on Young modulus E, coefficient of linear expansion $\alpha$ and on temperature difference on inner $(\mathrm{r}=\mathrm{a})$ and outer $(\mathrm{r}=\mathrm{b})$ surface.

\section{Mechanical stresses in thick-walled plunger subjected to external pressure $p$}

In pressing cycle, influence between plunger and tube with die of foundry machine with cold chamber with horizontal inundation chamber can model as Lame problem, so stress distribution in thin-walled plunger subjected to only external pressure $p$, as it is shown in figure 8. It is assumed that pressure inside of tube is equal to zero. In this work, only final relations were given to improve readability of the article. Detailed description of derivation of mathematical formulas can find in handbooks on strength of materials i.e.: [3, 6, 28, 29]. Applying used in this work signs, mathematical formulas on principal and mechanical stresses caused by uniformly distributed external pressure, are given as follows (13):

$$
\begin{aligned}
& \hat{\sigma}_{r}=\frac{p b^{2}}{a^{2}-b^{2}}-\frac{p a^{2} b^{2}}{r^{2}\left(a^{2}-b^{2}\right)} \\
& \hat{\sigma}_{t}=\frac{p b^{2}}{a^{2}-b^{2}}+\frac{p a^{2} b^{2}}{r^{2}\left(a^{2}-b^{2}\right)}
\end{aligned}
$$




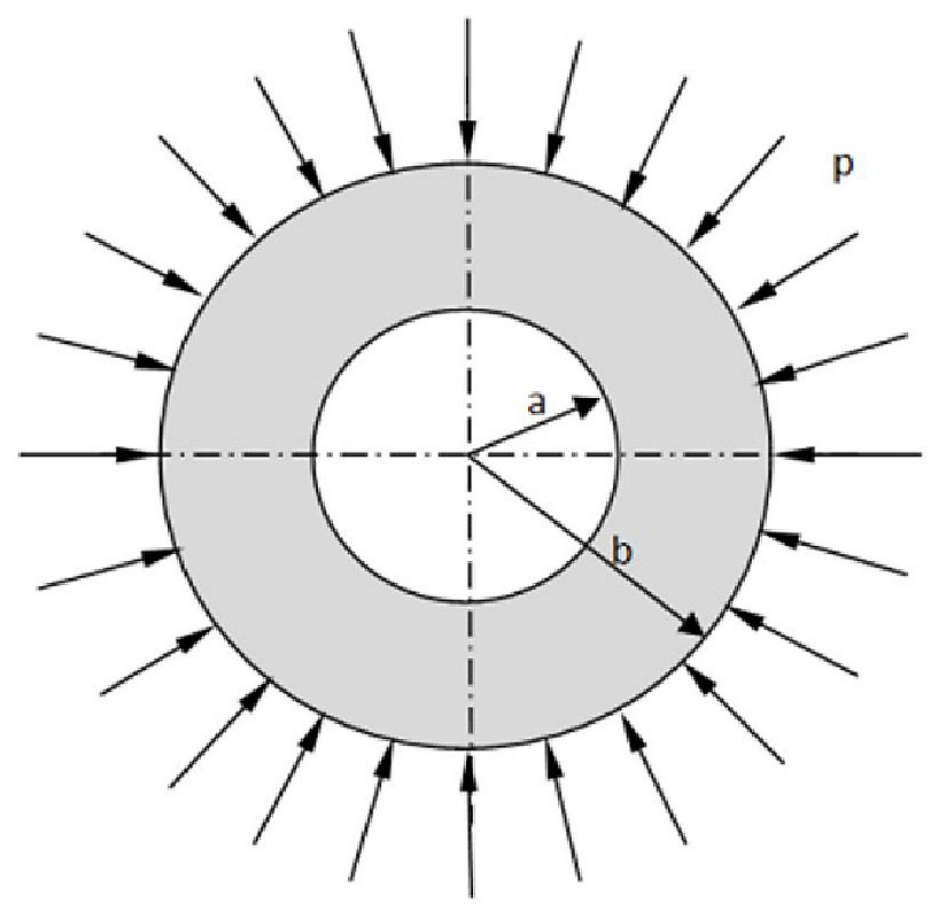

Fig. 8. Thick-walled cylindrical tube - plunger subjected external pressure

\section{Mechanical-thermal stresses in thick-walled plunger}

It was adopted the following additional assumption that axial stress does not depend on temperature and it was adopted that axial stress has uniform distribution. Axial stress is principal mechanical stress resulting from loading in work cycle of casting machine, which the highest value is assumed in process of subtending. In order to describe principal thermal-mechanical stresses in analysed tube, principle of superposition was used. On the basis of (12) and (13) finally was taken into account (14):

$$
\begin{aligned}
& \sigma_{r}=\bar{\sigma}_{r}+\hat{\sigma}_{r} \\
& \sigma_{t}=\bar{\sigma}_{t}+\hat{\sigma}_{t}
\end{aligned}
$$

\section{Equivalent stresses in plunger}

Having obtained principal stresses (14) $\sigma_{r}, \sigma_{t}, \sigma_{z}$ it can obtain moreover equivalent stresses for two the most well-known strength hypotheses: hypothesis of maximal shear stress $\tau_{\max }$ and hypothesis of Huber-Mises-Hencky HMH [3, $7,29]$. Material of plunger can have different maximal allowable stresses for tension $\mathrm{k}_{\mathrm{r}}$ and compression $\mathrm{k}_{\mathrm{c}}$ (or ultimate strength capacity for tension $\mathrm{R}_{\mathrm{m}}$ or for compression $\mathrm{R}_{\mathrm{c}}$ ). It was taken into account in two modifications of mentioned hypotheses: hypothesis Mohr and Burzynski [29].

For isotropic materials with the same ultimate strength capacity (obtained for tension and compression), equivalent stress was obtained according to the following hypotheses $[3,7,29]$ :

- Huber-Mises-Hencky (sign: HMH) (15):

$$
\begin{gathered}
\sigma_{H M H}=\left(\sigma_{e q v}\right)_{H M H}= \\
=\sqrt{\frac{1}{2}\left[\left(\sigma_{r}-\sigma_{t}\right)^{2}+\left(\sigma_{t}-\sigma_{z}\right)^{2}+\left(\sigma_{z}-\sigma_{r}\right)^{2}\right]} \leq k_{r} \\
\text { the highest shear stress } \tau_{\max }(\text { sign: TAU) (16): } \\
\sigma_{T A U}=\left(\sigma_{e q v}\right)_{T A U}=\left|\sigma_{\max }-\sigma_{\min }\right| \leq k_{r} \\
\text { where: } \sigma_{\max }=\max \left(\sigma_{r}, \sigma_{t}, \sigma_{z}\right) \\
\sigma_{\min }=\min \left(\sigma_{r}, \sigma_{t}, \sigma_{z}\right) .
\end{gathered}
$$

Obtaining of mechanical-thermal stress distribution gives ability to conduct parametric analysis and makes easy evaluation of tribology properties of tube. Whereas in case of isotropic materials having different allowable stresses for compression $\mathrm{k}_{\mathrm{c}}$ (or ultimate strength capacity for compression $\mathrm{R}_{\mathrm{c}}$ ) and tensions $\mathrm{k}_{\mathrm{r}}$ ( or ultimate strength capacity for tensions $\mathrm{R}_{\mathrm{m}}$ ) according to following hypotheses $[4,29]$ : 
- Burzynski (sign: B),

At the beginning two parameters should be calculated (17) i (18):

$$
\begin{gathered}
\omega_{1}=\left(\sigma_{r}+\sigma_{t}+\sigma_{z}\right) / 3 \\
\omega_{2}=\sqrt{\left(\sigma_{r}-\sigma_{t}\right)^{2}+\left(\sigma_{t}-\sigma_{z}\right)^{2}+\left(\sigma_{z}-\sigma_{r}\right)^{2}} / 3
\end{gathered}
$$

, which allow to calculate equivalent stress according to presented hypothesis for 3 conditions (19), (20) i (21):

$$
\begin{array}{lcc} 
& -\sqrt{2} \leq \omega_{2} / \omega_{1} \leq 0, \\
\text { than } & \sigma_{B}=\left(\sigma_{e q v}\right)_{B}=3 \omega_{2} /(\sqrt{2} z)<k_{r}
\end{array}
$$

$$
\begin{aligned}
& \text { if } \quad \omega_{2} / \omega_{1}<-\sqrt{2} \text { lub } \sqrt{2<\omega_{2} / \omega_{1},} \\
& \text { than } \sigma_{B}=\left(\sigma_{e q v}\right)_{B}=3(z+1) \omega_{2} /(2 \sqrt{2} z)+3(z-1) \omega_{1} /(2 z)<k_{r}
\end{aligned}
$$

$$
\begin{aligned}
& \text { if } \quad 0 \leq \omega_{2} / \omega_{1} \leq \sqrt{2}, \\
& \text { than } \sigma_{B}=\left(\sigma_{e q v}\right)_{B}=3 \omega_{2} /(\sqrt{2} z)+3(z-1) \omega_{1} / z<k_{r}
\end{aligned}
$$

- where (22):

$$
z=R_{c} / R_{m}=\left(k_{c} / k_{m}\right)
$$

- Mohr's (sign: M) (23):

$$
\sigma_{M}=\left(\sigma_{e q v}\right)_{M}=\left|\sigma_{\max }-\frac{1}{z} \sigma_{\min }\right| \leq k_{r}
$$

In case of $\mathrm{z}=1$, Burzynski hypothesis reduces to HMH hypothesis, and Mohr hypothesis to maximal shear stress TAU hypothesis.

For equations above, program was made to calculate components of principal stresses and equivalent stress for 4 hypotheses.

\section{ANALYSIS OF THE RESULTS}

Calculations were conducted for the following input data for real conditions, that appear during technology process using casting machine Bühler in company WIFAMA-PREXER:
- outer temperature of plunger:

- case $1-\mathrm{T}_{\mathrm{b}}=300{ }^{\circ} \mathrm{C}$,

- case $2-\mathrm{T}_{\mathrm{b}}=250^{\circ} \mathrm{C}$,

- case $3-\mathrm{T}_{\mathrm{b}}=200^{\circ} \mathrm{C}$;

- inner temperature of plunger $\mathrm{T}=150^{\circ} \mathrm{C}$;

- outer diameter of plunger $\mathrm{D}=2 \mathrm{~b}=70 \mathrm{~mm}$;

- inner diameter of plunger $\mathrm{d}=2 \mathrm{a}=42 \mathrm{~mm}$;

- maximal pressure of plunger $\sigma_{z}=-72 \mathrm{MPa}$;

- relation of different strengths $\mathrm{z}=\mathrm{k}_{\mathrm{c}} / \mathrm{k}_{\mathrm{r}}\left(\mathrm{R}_{\mathrm{c}} / \mathrm{R}_{\mathrm{m}}\right)$ $\mathrm{z}=1,5$;

- pressure on outer surface of plunger $\mathrm{p}=0$; $10 \mathrm{MPa} ; 20 \mathrm{MPa}$.

In work, it was assumed that plunger was made of one of variant according to Table 1 [1, 2 $11,17]$. In calculations, it was assumed that terms with index according to Table 1 for given material type. Accepted data above for plunger do not change because of conducting of easier comparative analysis. Three variants of temperature distribution were assumed. Temperature on outer surface of plunger was changed in range of $200^{\circ} \mathrm{C}-$ $300^{\circ} \mathrm{C}$ (cases $1-3$ ). As it is easy to notice that on the basis of formulas (12) the highest values of stresses are for the maximal difference of temperatures and that is why, in this work, only full curves for case were shown $\mathrm{T}_{\mathrm{b}}=300^{\circ} \mathrm{C} \mathrm{i} \mathrm{T}_{\mathrm{a}}=150^{\circ} \mathrm{C}$ (case 1). For remaining two variants, only curves of equivalent stresses were shown according to hypotheses HMH and Burzynski.

\section{Analysis of stress state of plunger for case $p=0$}

At the beginning case of lack of pressure on outer surface was investigated ( $\mathrm{p}=0$, Fig. 8). I means that stresses (13) are equal correspondingly to: $\hat{\sigma}_{r}=0, \hat{\sigma}_{t}=0$. In figures 9-16 curves of dependence of temperature and stresses for case 1 were shown- whereas $\mathrm{Tb}=300^{\circ} \mathrm{C}$ and $\mathrm{Ta}=150^{\circ} \mathrm{C}$. Number terms of curves correspond to terms of material variants (Table 1).

Assumed stress state causes that temperature distribution along plunger radius is identical for all 4 material variants (Fig. 9). Similar situation is

Table 1. Material data for plunger

\begin{tabular}{|c|c|c|c|c|c|c|c|c|}
\hline \multirow{2}{*}{ Variants } & \multirow{2}{*}{ Material } & $E$ & $v$ & $\alpha$ & $E \alpha$ & $R_{m}$ & $R_{c}$ & $z$ \\
\cline { 3 - 8 } & & $\mathrm{GPa}$ & - & $10^{-6} \mathrm{~K}^{-1}$ & $\mathrm{~Pa} / \mathrm{K}$ & $\mathrm{MPa}$ & $\mathrm{MPa}$ & - \\
\hline 1 & CuAl10Fe5Ni5 [17] & 110 & 0.34 & 16.2 & 1782 & 620 & 938 & 1.5 \\
\hline 2 & 50 standard grey iron [2] & 145 & 0.29 & 10.8 & 1566 & 362 & 1130 & 1.5 \\
\hline 3 & High silicon bronze A H-01 [11] & 105 & 0.346 & 18.0 & 1890 & 550 & & 1.5 \\
\hline 4 & Ampcoloy A 89 beryllium cooper [1] & 135 & 0.34 & 17.2 & 2322 & 740 & & 1.5 \\
\hline
\end{tabular}


for axial stress $\sigma_{z}(r)$ (Fig. 12) according to assumption. Tension radial stress $\sigma_{r}(r)$ (Fig. 10) does not exceed $22 \mathrm{MPa}$ for 4-th variant of material, but on outer and inner surfaces of plunger are equal to 0 according to boundary conditions. Angular stress $\sigma_{t}(r)$ (Fig. 11) changes in range of $-150<\sigma_{t}(r)<200 \mathrm{MPa}$, but for $\mathrm{r}=27,5 \mathrm{~mm}$ are equal to zero. On inner side, angular stress is tension stress but on outer side - compression one. In the next two figures (Fig. 13 and 14), change of equivalent stresses is shown according to $\mathrm{HMH}$ and TAU hypotheses. Values of stresses are changing in range of $70<\sigma_{\text {HMH }}(r)<250 \mathrm{MPa}$, $70<\sigma_{T A U}(r)<275 \mathrm{MPa}$, but lower values are obtained for HMH hypothesis. According to Burzynski hypothesis, equivalent stress (Fig. 15) are in range of $50<\sigma_{B}(r)<230 \mathrm{MPa}$ and are lower than stress according to HMH (Fig. 13). The highest differences are for $r>29 \mathrm{~mm}$, but on outer surface for hypothesis Burzynski are at least lower. Equivalent stress for Mohr hypothesis (Fig. 16) are changing in range of $50<\sigma_{M}(r)<250 \mathrm{MPa}$ and are greater than stress obtained according to $\mathrm{HMH}$ hypothesis. Comparing equivalent stresses obtained according to HMH and maximal shear stress hypotheses on outer surface are greater than according to Burzynski and Mohr hypotheses. For all investigated cases the highest value of stress are obtained for material variant 4 and then 3 and 1, but the lowest for variant 2 .

Equivalent stress on outer surface is greater than stress in short distance from the surface. The equivalent stress outside the plunger, that can name stress of outer top layer, decides on low-cycled fatigue strength of this layer. Stress of the outer top layer decides on durability of the tube and its reliability.

Consideration of all strength hypotheses should allow to more precise prediction of tribologic properties.

In Figures 17-20 curves for two remaining variants of temperature are shown:

- case $2-\mathrm{T}_{\mathrm{b}}=250^{\circ} \mathrm{C}$ and $\mathrm{T}_{\mathrm{a}}=150^{\circ} \mathrm{C}$ (Fig. 17, Fig. 18),

- case $3-\mathrm{T}_{\mathrm{b}}=200^{\circ} \mathrm{C}$ and $\mathrm{T}_{\mathrm{a}}=150^{\circ} \mathrm{C}$ (Fig. 19 , Fig. 20),

- but axial principal stress is equal to $-72 \mathrm{MPa}$.

Thermal, principal stresses $\sigma_{r}(r)$ and $\sigma_{t}(r)$ according to (12) are linear function of temperature difference $\Delta T=T_{b}-T_{a}$. The sense of sentence above decided so that distributions compared to Fig.10 and 11 for case 1 correspondingly, are not presented. In Fig. 17 and 18, only distributions of equivalent stresses $\mathrm{HMH}$ and B are shown for case 2 and in Fig. 19 and 20 stress distributions $\mathrm{HMH}$ and $\mathrm{B}$ for case 3 . According to expectancy, equivalent stresses go down with temperature difference (compare Fig. 13,15 with Fig. 17,18 and with Fig. 19,20). For $\Delta T=100^{\circ} \mathrm{C}$ equivalent stress $\mathrm{HMH}$ (Fig. 17) they change in range of $70 \mathrm{MPa}<\sigma_{\text {HMH }}(r)<185 \mathrm{MPa}$, but according to hypothesis Burzynski (Fig. 18) $50<\sigma_{B}(r)$ $<165 \mathrm{MPa}$. For third variant $\Delta T=50^{\circ} \mathrm{C}$ equivalent stress changes in range of $70 \mathrm{MPa}<\sigma_{H M H}(r)$ $<185 \mathrm{MPa}$ (Fig. 18) and $50<\sigma_{B}(r)<165 \mathrm{MPa}$ (Fig. 20). Stresses $\sigma_{H M H}(r)$ (Fig. 19) and $\sigma_{B}(r)$ (Fig. 20) go down, but radius goes up and belongs to range $a \leq r \leq b$ in opposite to curves in Fig. 13, 17 and Fig. 15, 18.

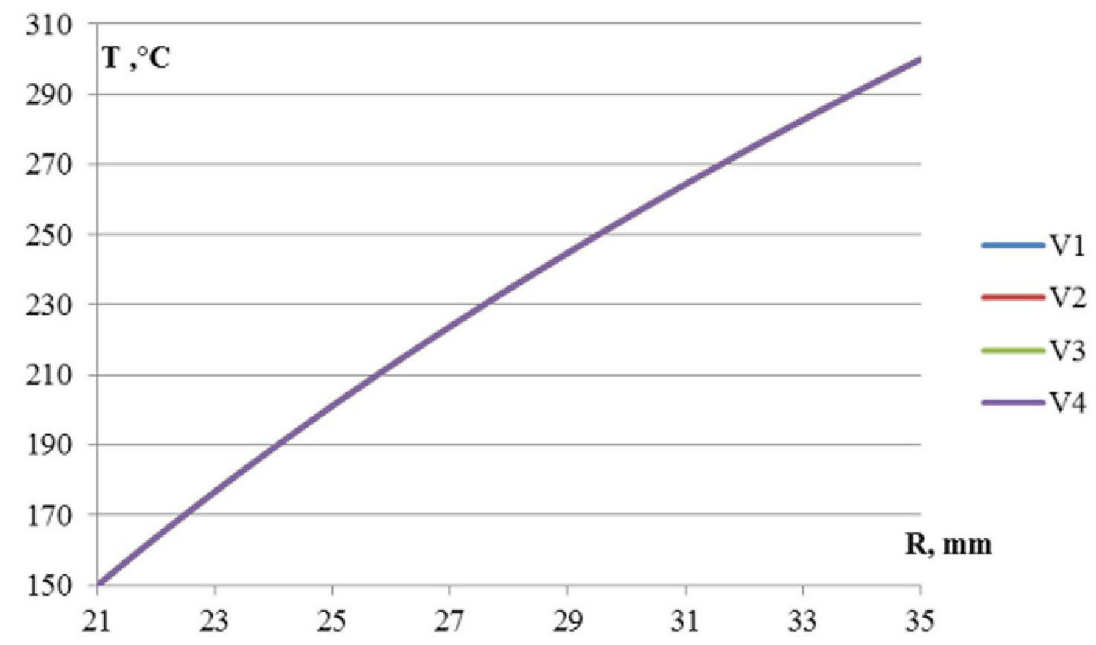

Fig. 9. Change of plunger temperature $T$ along radius $r$ for case 1 


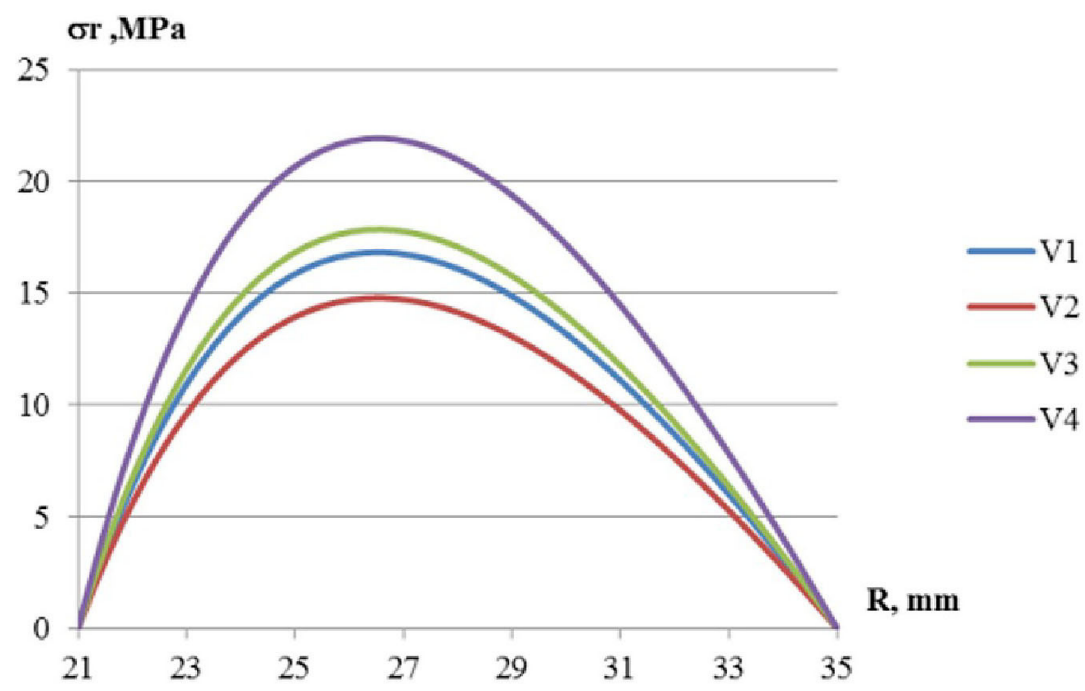

Fig. 10. Change of radial stresses $\sigma_{r}(r)$ for case 1

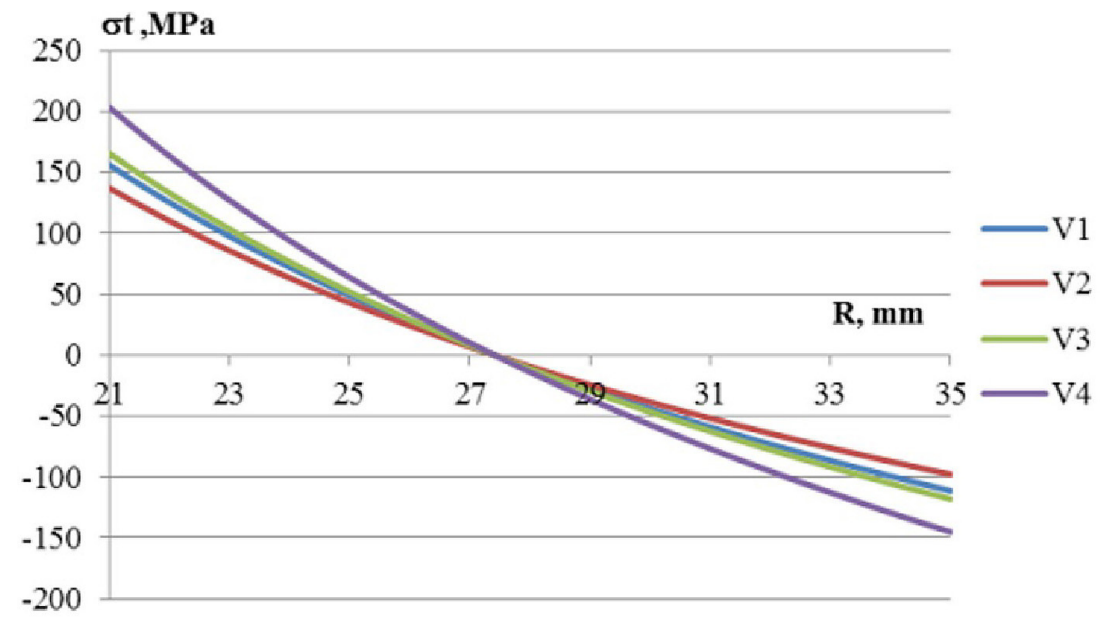

Fig. 11. Change for angular stresses $\sigma_{t}(r)$ for case 1



Fig. 12. Axial stresses $\sigma_{z}(r)$ for case 1 


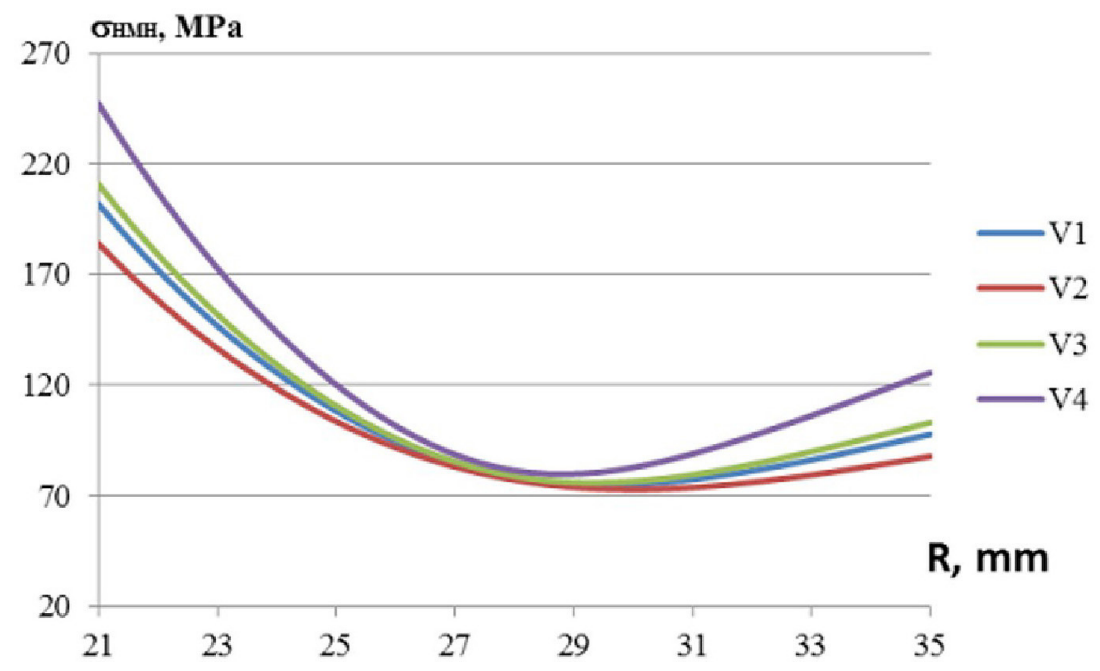

Fig. 13. Change of equivalent stresses $\sigma_{H M H}(r)$ for case 1

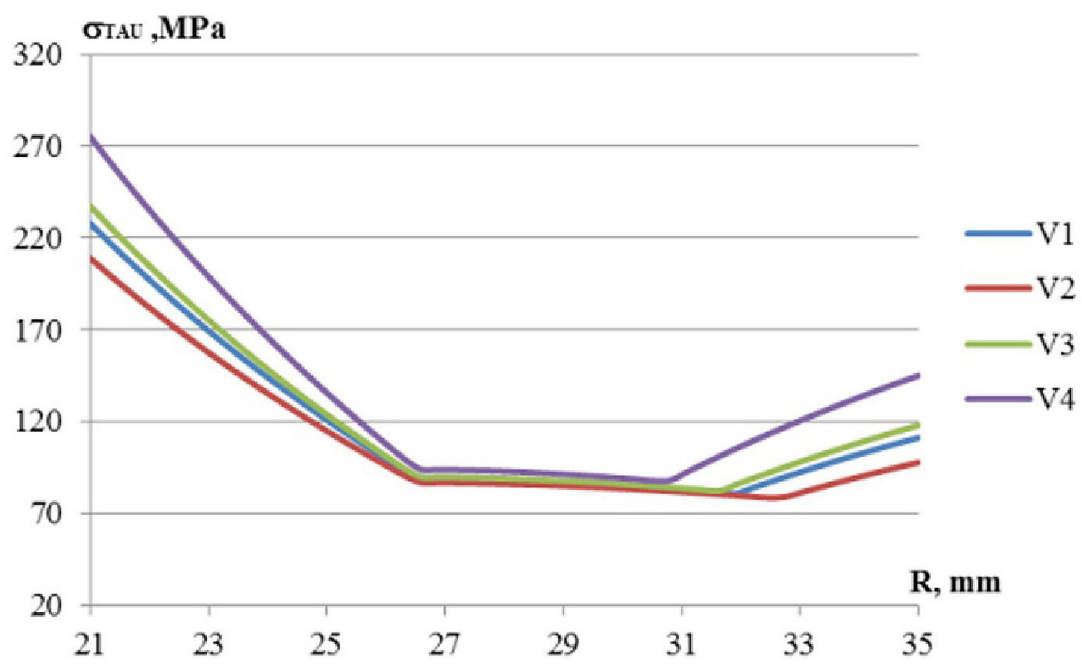

Fig. 14. . Change of equivalent stresses $\sigma_{T A U}(r)$ for case 1

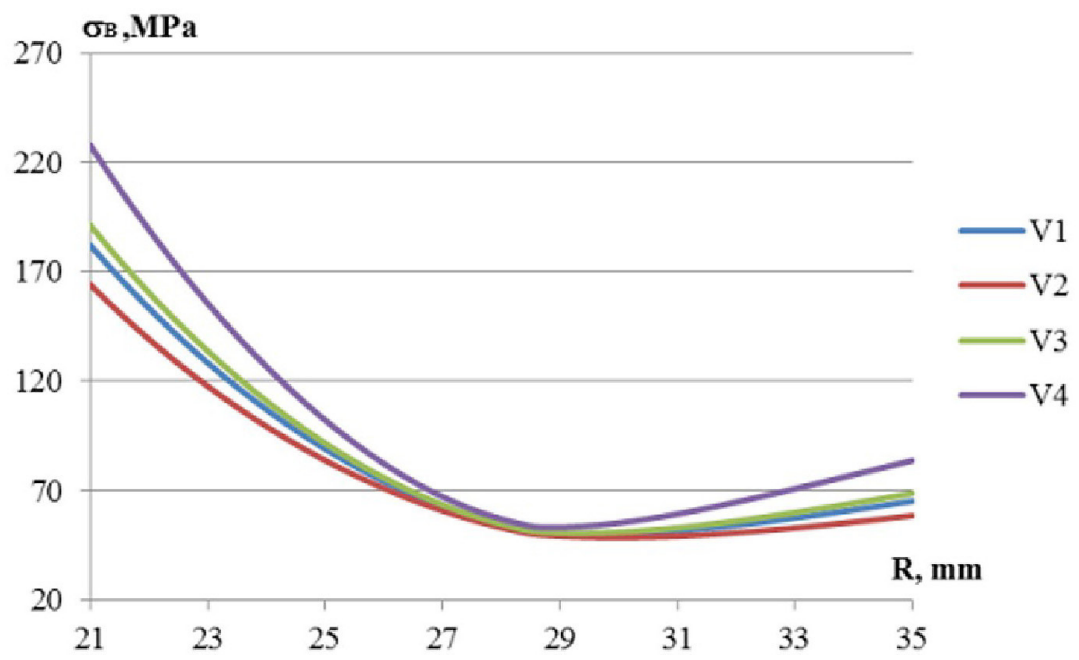

Fig. 15. Change of equivalent stresses $\sigma_{B}(r)$ for case 1 


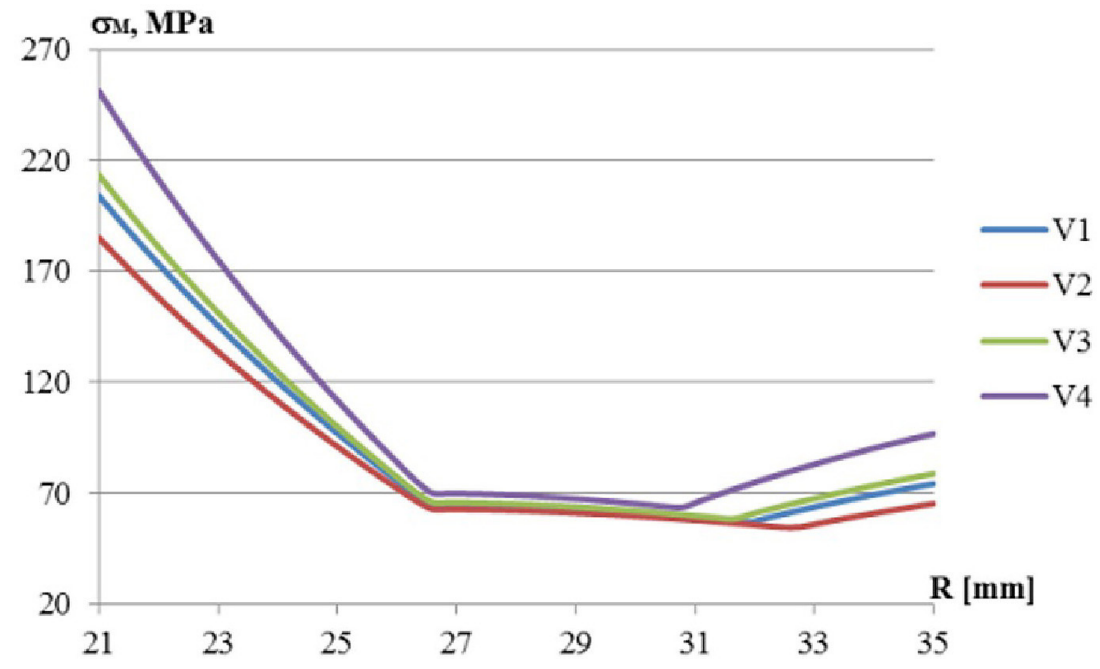

Fig. 16. Change of equivalent stresses $\sigma_{M}(r)$ for case 1

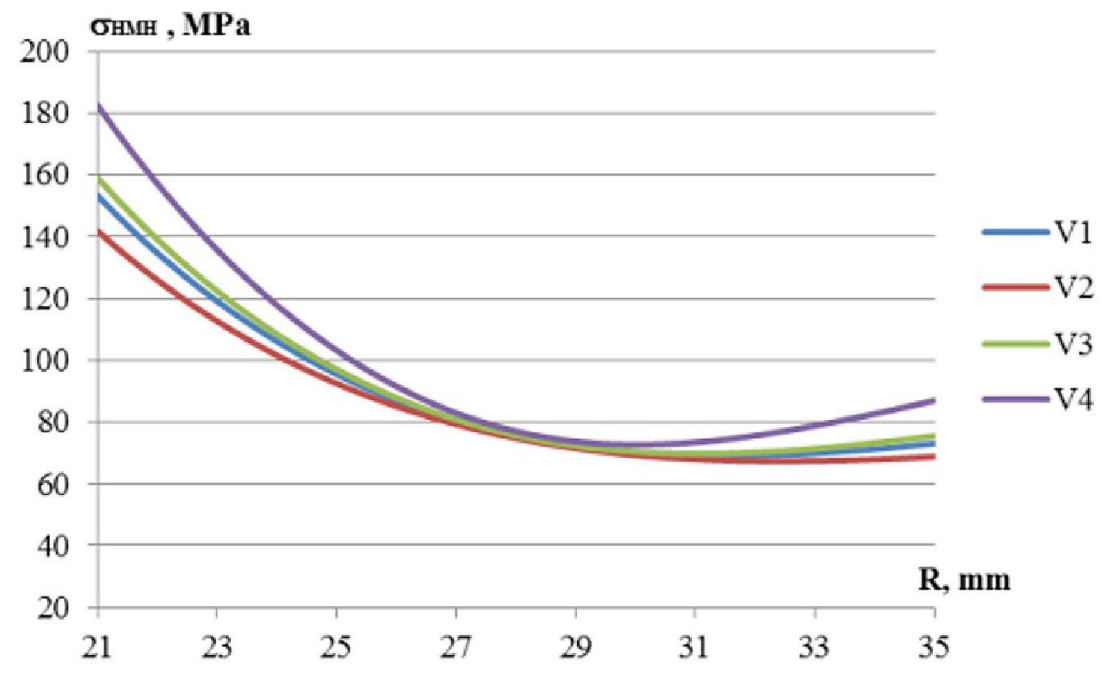

Fig. 17. Change of equivalent stress $\sigma_{H M H}(r)$ for case 2

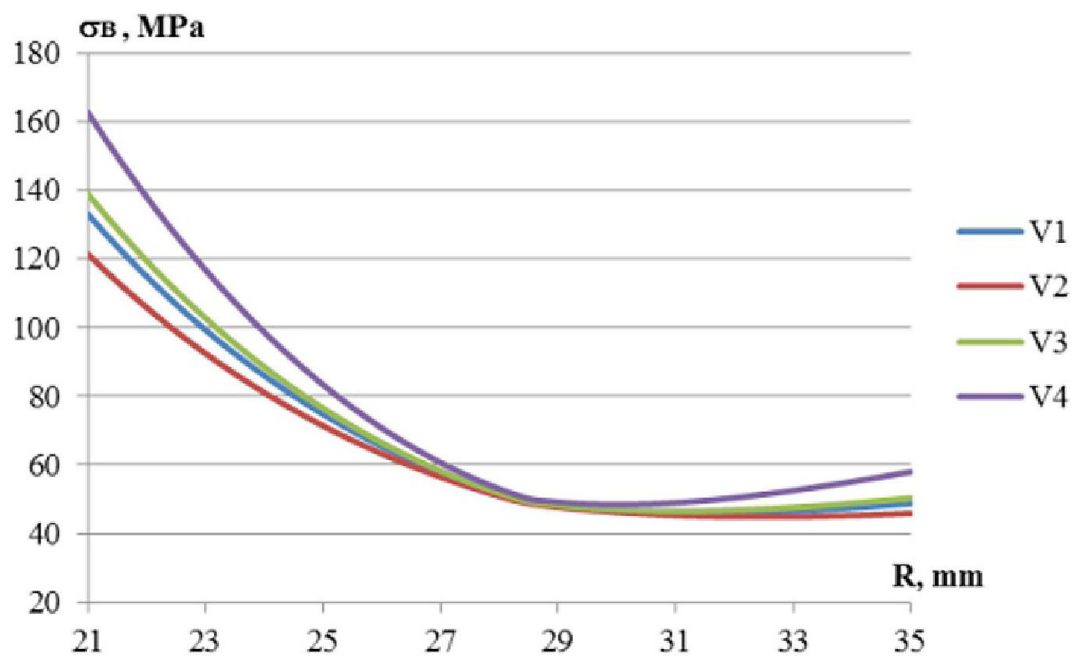

Fig. 18. Change of equivalent stress $\sigma_{B}(r)$ for case 2 


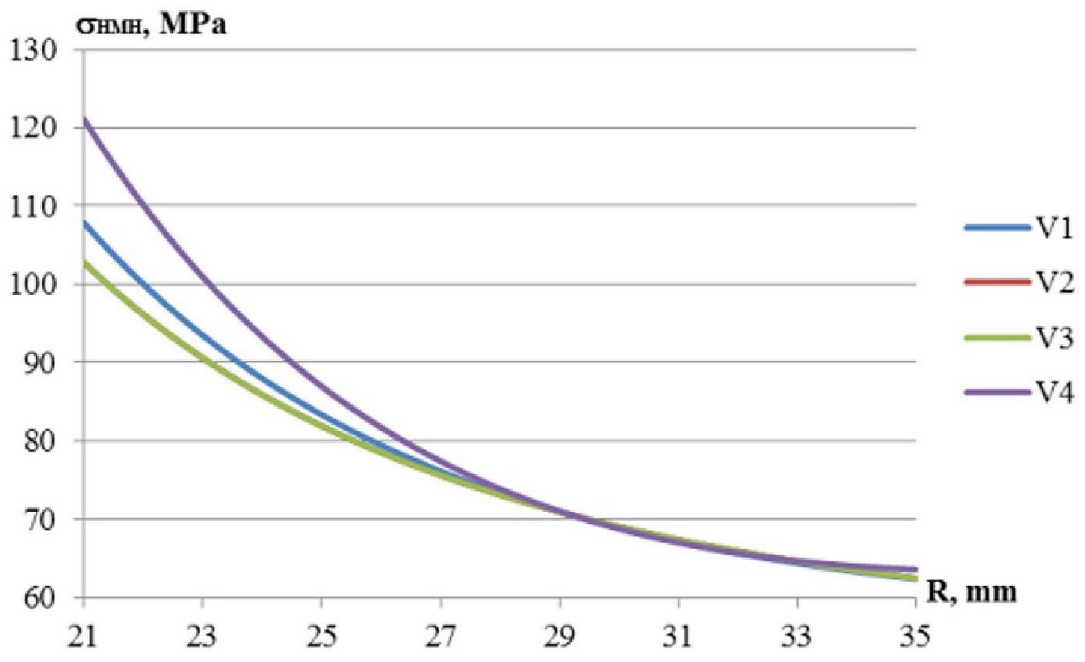

Fig. 19. Change of equivalent stress $\sigma_{H M H}(r)$ for case 3

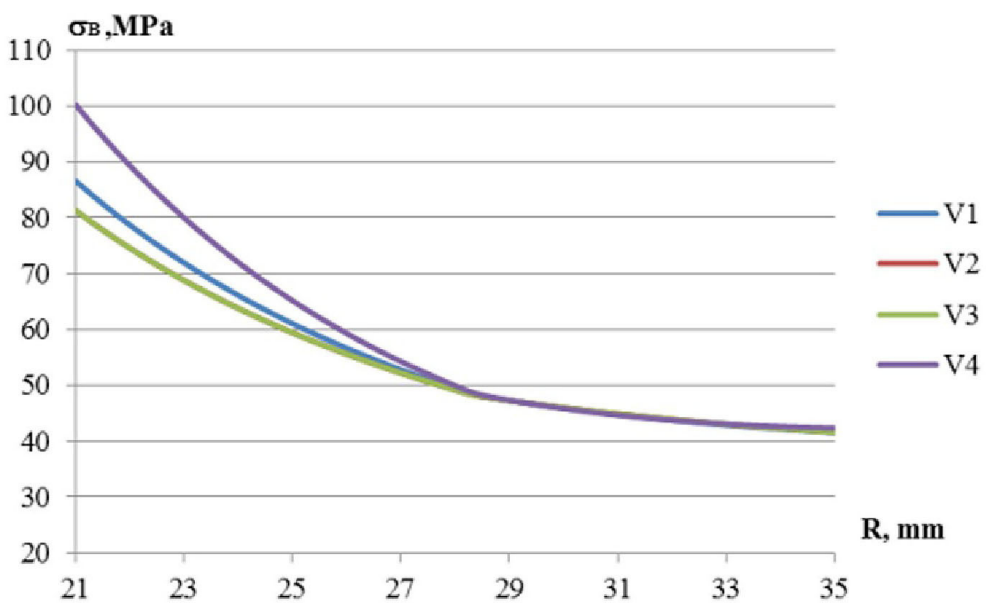

Fig. 20. Change of equivalent stress $\sigma_{B}(r)$ for case 3

Obtained distributions of thermal-mechanical stresses for various materials and temperature can be used for rational selection of plunger materials with desirable mechanical properties.

\section{Analysis of stress state of plunger for case $p \neq 0$}

Analysis of stress state in plunger during modelling of process of compression, that is for the case of acting pressure on outer surface of the plunger (Fig. 8), was conducted for: $\mathrm{p}=10 \mathrm{MPa}$ and $\mathrm{p}=20 \mathrm{MPa}$. In curves, case of lack of pressure $(p=0)$ is shown. In figures 21 and 22 curves of changing of equivalent stresses are shown, according to hypothesis: HMH $\sigma_{H M H}(r)$ and Burzynski $\sigma_{B}(r)$ only for case 1 when all loadings are taken into consideration in chapter 3.1. Equivalent stress $\sigma_{H M H}(r)$ (Fig. 21) on outer surface $(\mathrm{r}=\mathrm{b})$ are greater by assumed value of pressure $p$ compared to the case $p=0$. On inner surface they cause reduction of equivalent stresses about $60 \mathrm{MPa}$ for cases $\mathrm{p}=20 \mathrm{MPa}$ and $\mathrm{p}=0$. Similarly, curves can observe for $\sigma_{B}(r)$ (Fig. 22) with difference that on the outer surface stress $\sigma_{B}(r)$ are lower by about $30 \mathrm{MPa}$ than $\sigma_{\text {HMH }}(r)$, and for inner surface by $20 \mathrm{MPa}$ correspondingly.

\section{CONCLUSIONS}

In this work, analysis of stress state in plunger of casting machine with cold chamber was shown subjected to static mechanical and thermal stationary. Four various materials of plunger and three cases of temperature were investigated. Obtained principal stresses in plunger allow to calculate equivalent stresses according to four strength hypotheses, including two that taking 


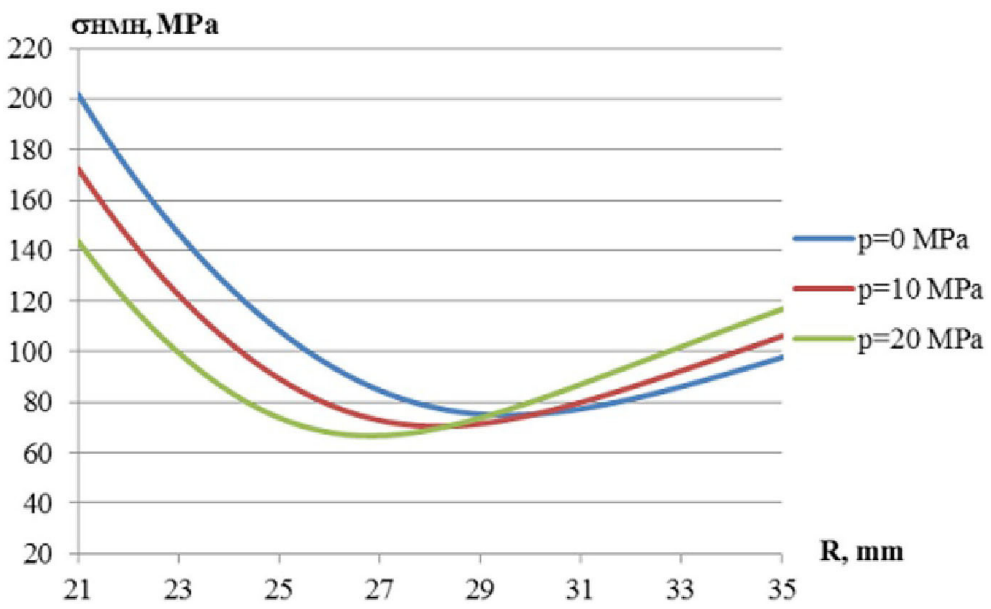

Fig. 21. Change of equivalent stress $\sigma_{H M H}(r)$ for case 1

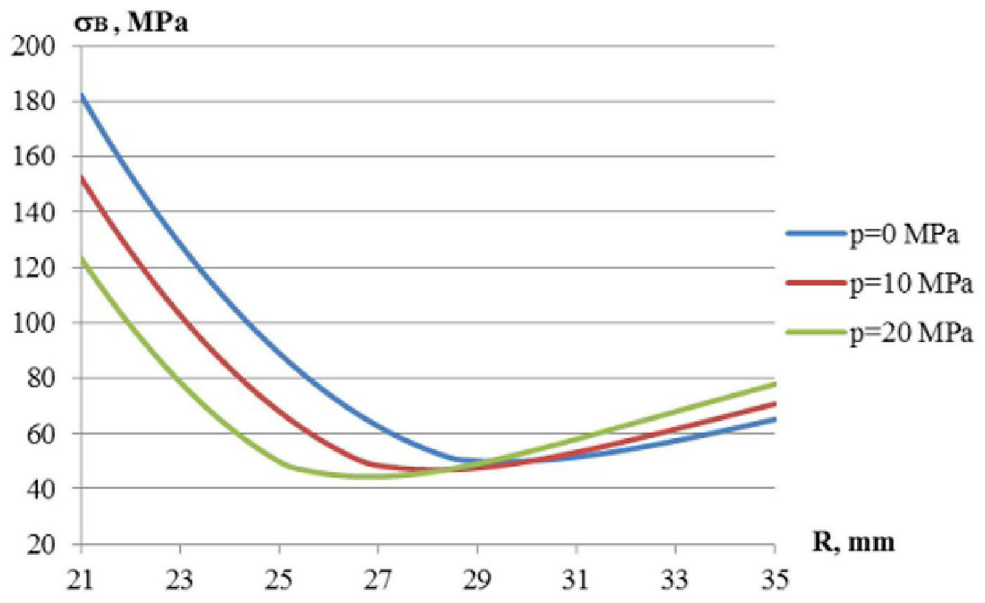

Fig. 22. Change of equivalent stress $\sigma_{B}(r)$ for case 1

into account various mechanical parameters (ultimate strength capacity) that deal with tension and compression. Analysis was supplemented by the case of acting of plunger on horizontal chamber of priming (tube) with die in the last process of casting. It allows to obtain more adequately equivalent stresses. It can allow on more rational selection of material on plunger of casting machine, taking into account conditions during work of machine and greater durability and reliability.

\section{REFERENCES}

1. Ampco Metal AMPCOLOY ${ }^{\circledR} 89$ Beryllium Copper, Extrusion. 1996-2019. http://www.matweb. com/search/DataSheet.aspx?MatGUID=0d4f6a $7 \mathrm{~b}$ c06644fa97fef02378a64a14 .

2. ASTM class 50 Standard gray iron test bars, as cast. 1996-2019. http://www.matweb.com/search/datasheet.aspx?matguid=aacd20ec069e4ce6a15a6c4d7

\section{$2037 \mathrm{ffd} \& \mathrm{ckck}=1$.}

3. Brzoska Z. Wytrzymałość materiałów. PWN, Warszawa 1983.

4. Burzyński W. Theoretical foundations of the hypotheses of material effort (Translated from the original paper in Polish "Teoretyczne podstawy hipotez wytężenia" Czasopismo Techniczne, 1929, 47, 1-41, Lwów by A. Stręk; scientific editor R.B. Pęcherski). Engineering Transactions, 56(3), 2008, 269-305.

5. Chien K., Samra J., Robbins P. Plunger Design and Materials - the Keys to Die Casting Success. Abst Head - Abstract heading, July, 2018. https://castool. com/wp-content/uploads/2018/08/Plunger-Tip-Design-Materials-07-2018-1.pdf .

6. Derski W. Podstawy teorii sprężystości. PWN, Warszawa, 1965.

7. Dyląg Z., Jakubowicz A., Orłoś Z. Wytrzymałość materiałów. WNT, Warszawa 2013.

8. Fajkiel A., Dudek P., Czekaj E. Trends in Development of Auxiliary Materials Used in Pressure Die 
Casting. Modern Foundry Poland and the World, 3-4, 2015, 6-14.

9. Fiorese E., Bonollo F., Battaglia E. A Tool for Predicting the Effect of the Plunger Motion Profile on the Static Properties of Aluminium High Pressure Die Cast Components. Metals, 8, 798, 2018. https:// doi: $10.3390 /$ met8100798 .

10. Handbook-Al-HPDC-Alloys-for-Structural-Casts RHEINFELDEN - ALLOYS_2017_EN.pdf. January, 2018. http://rheinfelden-alloys.eu/ wp-content/uploads/2018/01/Handbook-Al-HPDC-Alloys-for-Structural-Casts_RHEINFELDEN-ALLOYS_2017_EN.pdf.

11. Herculoy ${ }^{\circledR}$, High-Silicon Bronze A, UNS C65500, H01 Temper flat products. 1996-2019. http://www. matweb.com/search/DataSheet.aspx?MatGUID=25 7da2b59ba34da6a318504c6d759e08 .

12. Herman E. Control of Plunger Clearance. Information about High Pressure Die Casting HPDC Shot end Tooling Including Shot Sleeves and Plunger Tips. September, 2009. http://plungertipandshotsleeve.blogspot.com/ .

13. High Pressure Die Casting. https://www.faistgroup. com/what-we-do/processes/high-pressure-die-casting/.

14. Höök T. HPDC runner and gating system design. CAE DS -Mould Design. https://docplayer. net/29747489-Hpdc-runner-and-gating-system-design-1.html .

15. Kanlıkama B., Abuşoğlu A., Güzelbey I.H. Coupled thermoelastic analysis of thick-walled pressurized cylinders. International Journal of Energy and Power Engineering, 2(2), 2013, 60-68.

16. Miglierina F., Vianello B. Shotsleeve with Integral Thermal Regulation. Proceedings of 6th International Tooling Conference - The Use of Tool Steels: Experience and Research, Eds. Bergstrom J., Fredriksson G., Johansson M., Kotik O., Thuvander F. 2017, 1317-1341.

17. Nickel Aluminum Bronze, UNS C63200. 1996-2019. http://www.matweb.com/search/DataSheet.aspx?MatGUID=b068d51359304e6a94ebef 6a4e9f7f96

18. Pisarek BP. Abrasive wear of BA1055 bronze with additives of $\mathrm{Si}, \mathrm{Cr}$, Mo and/or W. Archives of Foundry Engineering, 8(3), 2008, 209-216.

19. Pisarek B. Aluminium bronzes with additions of, $\mathrm{Cr}$, Mo and/or W with high resistance to wear. Zeszyty Naukowe Nr 1141, Rozprawy Naukowe Z. 441, Wydawnictwo Politechniki Łódzkiej, Łódź, 2013 (in Polish).

20. Pisarek BP., Kołakowski D. Optimization of the
Die Casting Process of Thick-Wall Bush Made of Compound Aluminum Bronze. Congress Proceedings - Sciemtific \& Technical, 73rd World Foundry Congress "Creative Foundry", 23rd-27th September 2018, Kraków, Poland 2018, 317-318.

21. Pisarek BP., Kołakowski D., Pacyniak T. Analysis of the Causes of Cracks in a Thick-Walled Bush Made of Die-Cast Aluminum Bronze. Archives of Foundry Engineering, 16(4). 2016, 119-124.

22. Pisarek BP., Kołakowski D., Pacyniak T. Simulation of Stress Distribution in a Thick-Walled Bushing Produced by Die-Casting. Archives of Foundry Engineering, 17(4), 2017, 127-132.

23. Qi Shi MS. Prediction of Thermal Distortion and Thermal Fatigue in Shot Sleeves. Dissertation, Advisor: Miller A. Presented in Partial Fulfilment of the Requirements for the Degree Doctor of Philosophy in the Graduate School of The Ohio State University, USA, 2002. https://etd.ohiolink.edu/!etd. send_file?accession $=$ osu $1034967167 \&$ disposition $=$ inline .

24. Robbins P., Chien K. High Pressure Die Casting Structural Aluminum. 2014. http://castool. com/wp-content/uploads/2018/08/High-Pressure-Die-Casting-Links-2014.pdf .

25. PIW Wifama-Prexer Łódź Poland, 2014. http:// www.wifama.com.pl/ .

26. Silva E., Úbeda V., Fischer W. Shot Sleeves for Die Casting (Thermal Variations and its Consequences) Proceedings of the Foundry Congress: CONAF 2009, 22 to 25 September 2009, Sao Paulo, Brazil 2009. http://wfischer.com.br/en/files/CONAF-paper.pdf .

27. Smetan H. Contribution to Solving an Inherent Problem When High Pressure Die-Casting Aluminium and its Alloys. Journal of Materials Science and Engineering, B 6 (5-6), 2016, 131-143. http://doi:1 0.17265/2161-6221/2016.5-6.003

28. Timoshenko S., Goodier JN. Teoria sprężystości. Wydawnictwo Arkady, Warszawa 1962.

29. Walczak J. Wytrzymałość materiałów oraz podstawy teorii sprężystości i plastyczności. PWN, Warszawa-Kraków, 1978.

30. Wen-bo Y., Yong-you C., Zhi-peng G., Shou-mei X. Development and application of inverse heat transfer model between liquid metal and shot sleeve in high pressure die casting process under non-shooting condition. China Foundry, 13(4), 2016, 269-275.

31. Cold Chamber Die Casting Plunger Tips and Shot Sleeves Retrieved March 11, 2019. http://plungertipandshotsleeve.blogspot.com/2009/09/control-of-plunger-clearance.html 